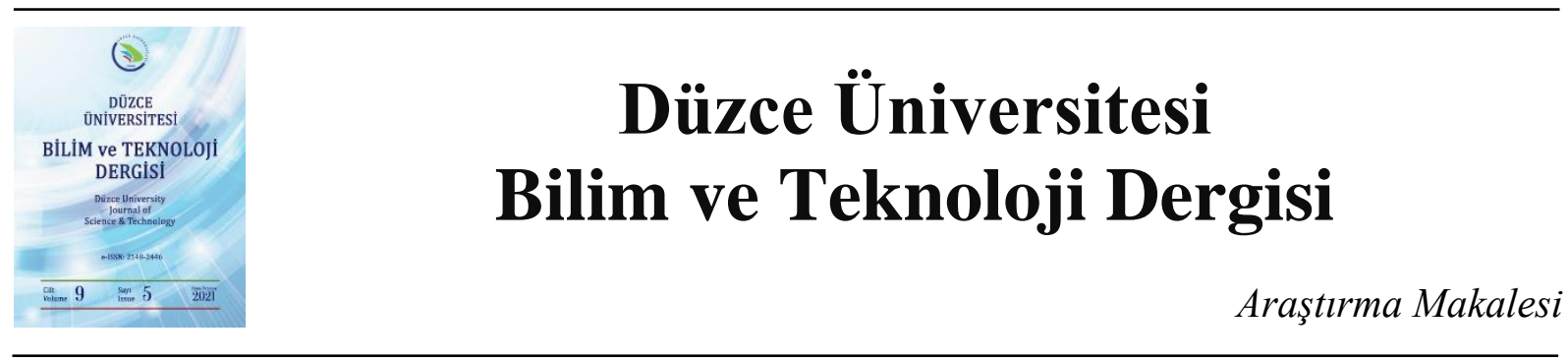

\section{Nevşehir İli Hava Kalitesinin Markov Zinciri ile Tahmini}

\author{
Emine BAŞTÜRK ${ }^{\mathrm{a}, *}$, (D) Alper ALVER a \\ a Teknik Bilimler Meslek Yüksekokulu, Çevre Koruma Teknolojileri Bölümü, Aksaray Üniversitesi, 68100, \\ Aksaray, Türkiye. \\ * Sorumlu yazarın e-posta adresi:eminebasturk@hotmail.com.tr
}

DOI: $10.29130 /$ dubited.885779

\begin{abstract}
$\underline{\mathrm{O} Z}$
$\mathrm{Bu}$ makalede Nevşehir İlinde $\mu \mathrm{g}$ m-3 seviyesinde bulunan $\mathrm{PM}_{10}, \mathrm{SO}_{2}, \mathrm{CO}, \mathrm{NO}_{2}$ ve $\mathrm{O}_{3}$ gibi temel hava kirletici parametreleri 01.08.2019-19.11.2020 tarihleri arasında izlenilmiş ve bu parametrelere bağlı olarak Hava Kalite İndeksi (HKİ) değerleri hesaplanmıştır. Nevşehir İli HKİ değerleri iyi ve hassas dereceler arasında değişkenlik göstermektedir. HKİ izleme verileri kullanılarak Küçük Ölçekli ve Ayrık Zamanlı Markov Zinciri Modelleri eğitilmiş ve 20.11.2020-20.12.2020 tarihlerini kapsayan yeni verilerle doğrulamaları yapılmıştır. Yapılan bu çalışmada Nevşehir İli HKİ değerleri, Küçük Ölçekli ve Ayrık Zamanlı Markov zincir modelleri ile sırasıyla 0,887 ve 0,982 oranında başarıyla tahmin edilmiştir. Nevşehir İli hava kalitesine bağlı olarak daha az değişken duruma sahip olan Ayrık-Zamanlı Markov Zinciri Modeli hem eğitimde hem de kontrolünde kullanılan HKİ verilerini tahmin etmede daha başarılı bulunmuştur. Sonuç olarak Markov Zinciri modellerinin farklı hava koşullarını tahmin etmede başarılı bir yöntem olarak kullanılabileceği belirlenmiştir.
\end{abstract}

Anahtar Kelimeler: Hava kirliliği, Hava kalite indeksi, Markov zinciri, Model, Nevşehir, Tahmin.

\section{Prediction of Nevşehir Province Air Quality with Markov Chain}

\section{ABSTRACT}

In this article, basic air pollutant parameters such as $\mathrm{PM}_{10}, \mathrm{SO}_{2}, \mathrm{CO}, \mathrm{NO}_{2}$, and $\mathrm{O}_{3}$ at $\mu \mathrm{g}$ m-3 level in Nevșehir Province were monitored between 01.08.2019-19.11.2020 and Air Quality Index (AQI) values were calculated depending on these parameters. Nevşehir Province AQI values vary between good and sensitive degrees. While monitoring data were used in the training of the models, the data calculated between 20.11.2020-20.12.2020 and not used in the training of the models were also used in the checking. In this study, Nevşehir Province AQI values were successfully predicted using small-scale and discrete-time Markov Chain Models at 0.887 and 0.982 , respectively. The discrete-time Markov Chain Model, which has less variable status depending on the air quality of Nevşehir Province, has been found to be more successful in predicting the AQI data used both in training and checking. As a result, it has been revealed that Markov Chain models can be used as a successful method to predict different weather conditions.

Keywords: Air pollution, Air quality index, Markov Chain, Model, Nevşehir, Forecast. 


\section{GIRIS}

$\mathrm{Su}$, toprak ve hava hayatın temel taşlarıdır. Genel olarak, hızlı kentleşme ve sanayileşme nedeniyle hava kalitesi dünya çapında kötüleşmektedir [1]. Kentsel alanlarda hızla artan nüfusun iskan, tüketim, sağlık ve enerji ihtiyaçlarını karşılamak için yapılan eylemler, modern şehirlerde hava kirliliği oluşturan birçok soruna yol açmıştır [2]. Dünya Sağlık Örgütü (DSÖ 2006) tarafindan yürütülen detaylı bir araştırma da dünya nüfusunun yaklaşı \% $\% 90$ 'ının sürekli olarak hava kirliliği ile temas halinde olduğunu ve bunun da yılda iki milyonu aşan erken ölümlerle sonuçlandığını ortaya çıkarılmıştır [3]. Bu nedenle, hava kirliliği sorunu halk sağlığını tehdit eden önemli bir sorun haline gelmiştir [4, 5].

Halk sağlığı ile ilgili kaygılar nedeniyle, birçok ülke yalnızca hava kirleticilerinin emisyon seviyelerini azaltmak için düzenlemeler ve stratejiler uygulanmakla kalmaz, aynı zamanda hava kalitesini ölçmek için hava kalitesi izleme ağları kurmaktadır [6]. Teknolojinin gelişmesiyle birlikte izlenen veriler, kentsel hava kalitesine ilişkin farkındalığı artırmak için sürekli paylaşılmaktadır. Öte yandan izleme verileri, bir kontrol politikası veya stratejisinin etkinliğini değerlendirmek ve hava kalitesini tahmin etmek için sağlam bir temel olarak kabul edilir [7]. Günümüzde birçok araştırmacı, hava kalitesi verilerini ve belirli bir zaman dilimindeki hava kirleticilerinin dinamik özelliklerini belirlemek için zaman serisi analizi ve sinir ağları gibi çeşitli istatistiksel yaklaşımlar kullanmaktadır [8-10]. Hem eğilim hem de mevsimsellik, uzun vadeli verilerin zaman serileri tekniği ile analiz edilmesiyle elde edilebilir, ancak kısa vadeli veriler oldukça stokastik görünmektedir. Bu nedenle, kısa vadeli tahminlerde zaman serisi modellerinin kullanılması gerçekleştirilen tahminlerde genellikle durağanlık ve sapmalar gibi istenmeyen etkiler oluşturmaktadır. Ayrıca, stokastik özellikler araştırmaların güvenilirliğini ve geçerliliğinin sorgulanmasına sebep olmakta [11] ve aynı zamanda temel amaç olan hava kalitesi tahminlerinin tutarlı ve incelenebilir olmasını engellemektedir [7]. Aslında toplum, belirli bir kirleticinin doğru bir şekilde tahmin edilmesinden daha çok, hava kirliliği olayının meydana gelme olasılığ hakkında endişe duymaktadır [12].

Gerçek dünyadaki sorunları çözmek için iyi bilinen birçok tahmin yöntemi vardır; otoregresiv averaj modeli, mevsimsel otoregresif model, yapay sinir ağları ve empirik hibrit vb. Her tahmin modelinin gerçek ve karmaşık olan problemleri çözmek için diğerlerine nazaran farklı avantajları vardır. Problemin oluşmasına sebep olan etkenlerin karşıllklı ilişkilerini belirlemek için Markov zinciri modeli geliştirilen önemli araçlardan biridir [13]. Markov zinciri, stokastik sürecin özel bir durumudur [14]. Son zamanlarda, sistemin gözlem durumlarından geçiş matrisini tahmin etmek için kullanılmıştır [15]. Markov zincir modelinin geliştirilmesindeki ana bileşenler durum geçiş matrisi ve olasıllktır; her ikisi de dinamik değişimin tüm temel parametrelerini özetlemektedir. Model, maksimum olasılık yöntemine ve doğrusal programlama denklemine dayanmaktadır. Literatürde HKİ'yi tahmin etmek için kullanılan Markov zinciri çalışmaları yeterli seviyede değildir. Hava kirliliği ile ilgili tahminlerde bulunabilecek birkaç çalışma bulunmaktadır [16-18]. Diğer tahmin yöntemlerinin aksine, önerilen Markov zinciri yönteminin hesaplanması kolaydır ve dinamik değişim mekanizmaları hakkında derinlemesine bilgi gerektirmez. Dolayısıyla, verilerden anlam çıkarmak nispeten kolaydır. Hava kirliliği ve iklim değişikliği, canlı sağlığını, tarımsal ürünleri, orman ve ekosistem türlerini etkileyen önemli konulardan biridir ve devam eden bir sorundur. Hava kalitesi tahmini, hava kirliliğinin planlanmasında ve kontrolünde hayati bir rol oynamaktadır. Yapılan olan tahminler, bireylerin sağlıksız hava kirliliğine maruz kalmadan önce ihtiyati tedbirler almalarına olanak tanıyan hava kalitesi bilgilerini halka sağlamaktadır. Yukarıda bahsedilen Markov zincir modeline ek olarak, hava kalitesi ile ilgili olarak aynı yöntemi kullanan birkaç çalışma vardır. Suhaimi, vd. [19] Markov zinciri Monte Carlo kullanarak hava kalitesi veri setlerindeki eksik verileri ele almıştır. Ayrıca, bir Markov zinciri yöntemi de astım hastası olan yaşlı insanlar için hava kirliliğinin ciddi etkilerini ölçmek için kullanılmıştır [20]. Hava izleme istasyonlarının kümelenmesi [21], ortamdaki nitrojen dioksit seviyelerinin tahmin edilmesi [22] ve iç mekan havasındaki kirletici konsantrasyonunun modellenmesi [23] gibi çeşitli problemlerde de başarıyla uygulanmıştır.

Bu çalışmada, kısa ve uzun vadeli hava kalite indeksini tahmin etmek ve belirli bir alandaki başlıca hava kirleticileri belirlemek için bir yöntem önermeyi amaçlamaktadır. Nevşehir İli hava kalitesinin 
durumunu tanımlamak için küçük ölçekli ve ayrık zamanlı Markov zincirlerinden türetilen olasılık yaklaşımı kavramı kullanılmıştır. $\mathrm{PM}_{10}, \mathrm{SO}_{2}, \mathrm{CO}, \mathrm{NO}_{2}$ ve $\mathrm{O}_{3}$ içeren temel hava kirleticilerinin derişimleri Ulusal HKİ standardı açısında gözetilerek hava kalitesinin temiz ve kirli olma durumu için modellerde kullanılmak üzere farklı senaryolar oluşturulmuştur. Öncelikle oluşturulan senaryoların 01.08.2019-19.11.2020 tarihleri arasında gerçekleşme durumları belirlenerek modeller eğitilmiş ve sonrasında, 01.08.2019-20.12.2020 tarihleri arasında hangi senaryoların oluşacağı tahmin edilmiştir.

\section{MATERYAL VE METOT}

\section{A. İSTASYON ve VERI SETI}

Bu çalışma, HKİ tahminleri 01.08.2019 ve 19.11.2020 tarihleri arasında Nevşehir ili merkez konumunda CSB-GIA THM istasyonundan alınan verilerle gerçekleştirilmiştir. Örneklerin ele alındığı enlem ve boylam koordinatları 34,7014 ve 38,6232'dir. Model eğitiminin tarih aralığı 01.08.2019-19.11.2020 ve modelin doğrulanma tarih aralığı 01.08.2019-20.12.2020'dir. Toplam veri sayısı eğitim için 477, doğrulama için ise 507'dır. HKİ, belirli bir alandaki hava kalitesinin durumunun göstergesidir. $\mathrm{PM}_{10}$, $\mathrm{SO}_{2}, \mathrm{CO}, \mathrm{NO}_{2}$ ve $\mathrm{O}_{3}$ parametrelerinin ortalama hava kirletici konsantrasyonlarına göre hesaplanmaktadır. HKİye göre hava kirliliği 6 kategoride incelenmiştir. Bu kategoriler Tablo 1'de gösterilmiştir.

\section{B. HAVA KALITE İNDEKSI}

Gelişmiş teknolojik cihazlar hava kalitesini izlemek için kullanılmakta ve bu verileri halka duyurmak için periyodik raporlar yayınlanmaktadır. Genel olarak, ham veriler veya zaman serisi grafikleri ve istatistiksel analizler, anlaşılabilir bilgileri halka etkili olarak aktaramamaktadır [24]. Bu nedenle, Amerika Birleşik Devletleri Çevre Koruma Ajansı, ücretsiz olarak tüm hükümetler tarafından kullanılmak üzere 1976'da Kirletici Standart İndeksinin yerine Hava Kalitesi İndeksini uygulamaya koymuştur. HKİ, günlük hava kalitesi ve ilgili sağlık etkileri hakkında halka bilgi aktarmaktadır. HKİ, beş alt indeksi kapsayan maksimum alt indeks yaklaşımına dayanmaktadır: $\mathrm{PM}_{10}, \mathrm{SO}_{2}, \mathrm{CO}, \mathrm{NO}_{2}$, ve $\mathrm{O}_{3}$ [4]. Hava kalite indeksi hesabı Denklem (1 ve (2'de gösterilmiştir.

$H K \dot{I}_{i}=\frac{H K \dot{I}_{y}-H K \dot{I}_{d}}{C_{y}-C_{d}}\left(C_{i}-C_{d}\right)+H K \dot{I}_{d}$

$\mathrm{HKI}=\operatorname{maks}\left(\mathrm{HKI}_{1}, \mathrm{HKI}_{2}, \ldots, \mathrm{HKI}_{\mathrm{n}}\right)$

HKI $_{i}$ kirleticinin alt indeksidir, $C_{i}$ i kirleticisinin ortalama derişimidir, $C_{d}$ i kirleticisinin düşük kontrol limit derişimidir, $C_{y}$ ise i kirleticisinin üst kontrol limit derişimidir, $H K \dot{I}_{y}$ and $H K \dot{I}_{d}$ ise $C_{d}$ ve $C_{y}$ derişim değerlerindeki hava kalite indeks değerleridir. Hava kalite indeks değeri 50'ye eşit ve/veya düşük olduğunda, hava kalitesinin iyi olduğunu ve kirletici derişiminin düşük olduğunu gösterir. Hava kalite indeksi 50'den büyükse kirletici maksimum hava kalite indeksine sahip olduğunu göstermektedir. 
Tablo 1. Ulusal HKI standard ve temel hava kriletici parametrelerinin konsantrasyonu

\begin{tabular}{|c|c|c|c|c|c|c|c|c|c|}
\hline \multicolumn{2}{|c|}{$\begin{array}{l}\text { Küçük Ölçekli } \\
\text { Markov Zinciri } \\
\text { Modeli }\end{array}$} & $\begin{array}{r}\text { Ayrık- } \\
\text { Marko } \\
\mathrm{Mc}\end{array}$ & $\begin{array}{l}\text { Zimanli } \\
\text { Zinciri } \\
\text { deli }\end{array}$ & \multirow{2}{*}{$\begin{array}{l}\text { HKİ } \\
\text { Limiti }\end{array}$} & \multirow{2}{*}{$\begin{array}{c}\mathrm{PM}_{10} \\
\left(\mu g m^{-3}\right)\end{array}$} & \multirow{2}{*}{$\begin{array}{c}\mathrm{SO}_{2} \\
\left(\mu g m^{-3}\right)\end{array}$} & \multirow{2}{*}{$\begin{array}{c}\mathrm{CO} \\
\left(\mu g m^{-3}\right)\end{array}$} & \multirow{2}{*}{$\begin{array}{c}\mathrm{NO}_{2} \\
\left(\mu g m^{-3}\right)\end{array}$} & \multirow{2}{*}{$\begin{array}{c}\mathrm{O}_{3} \\
\left(\mu g m^{-3}\right)\end{array}$} \\
\hline $\begin{array}{l}\text { İndeks } \\
\text { Tanımı }\end{array}$ & $\begin{array}{l}\text { Indeks } \\
\text { Değeri }\end{array}$ & $\begin{array}{l}\text { İndeks } \\
\text { Tanımı } \\
\end{array}$ & $\begin{array}{l}\text { İndeks } \\
\text { Değeri }\end{array}$ & & & & & & \\
\hline İyi & 1 & Temiz & 0 & $0-50$ & $0-50$ & $0-100$ & $0-5500$ & $0-100$ & $0-120$ \\
\hline Orta & 2 & Kirli & 1 & $51-100$ & $51-100$ & $101-250$ & 5501-10000 & $101-200$ & $121-160$ \\
\hline Hassas & 3 & Kirli & 1 & $101-150$ & $101-260$ & $251-500$ & $10001-16000$ & $201-500$ & $161-180$ \\
\hline Sağlıksız & 4 & Kirli & 1 & $151-200$ & $261-400$ & $501-850$ & $16001-24000$ & $501-1000$ & $181-240$ \\
\hline Kötü & 5 & Kirli & 1 & $201-300$ & $401-520$ & $851-1100$ & $24001-32000$ & $1001-2000$ & $241-700$ \\
\hline Tehlikeli & 6 & Kirli & 1 & $>301$ & $>521$ & $>1101$ & $>32001$ & $>2001$ & $>701$ \\
\hline
\end{tabular}

\section{MARKOV ZİNCİR ANALİZi}

Bu çalışmada uzun ve kısa süreli hava tahminlerinin gerçekleştirilebilmesi için Markov zincir analizi kullanılmıştır. Önerilen yöntem, istatistiksel bağımlılığın en basit yolunu tanıtan stokastik bir süreçtir. Ek olarak, bu sürecin gelecekteki davranışı geçmiş davranışla ilgili değildir. Bu, $\mathrm{n}$ zamanından önceki geçmişine bakılmaksızın, başka bir $\mathrm{j}$ durumuna geçiş yapma olasılığının sadece i durumuna bağlı olduğunu gösterir. $\mathrm{Bu}$ durumda sadece kısa bir süre için mi yoksa uzun bir süre için mi olduğunun önemli olmadığına dikkat edilmelidir.

\section{1. Küçük Ölçekli Markov Zinciri Modeli}

Küçük ölçekli Markov zinciri yönteminin yapısı Şekil 1'de görselleştirilmiştir.

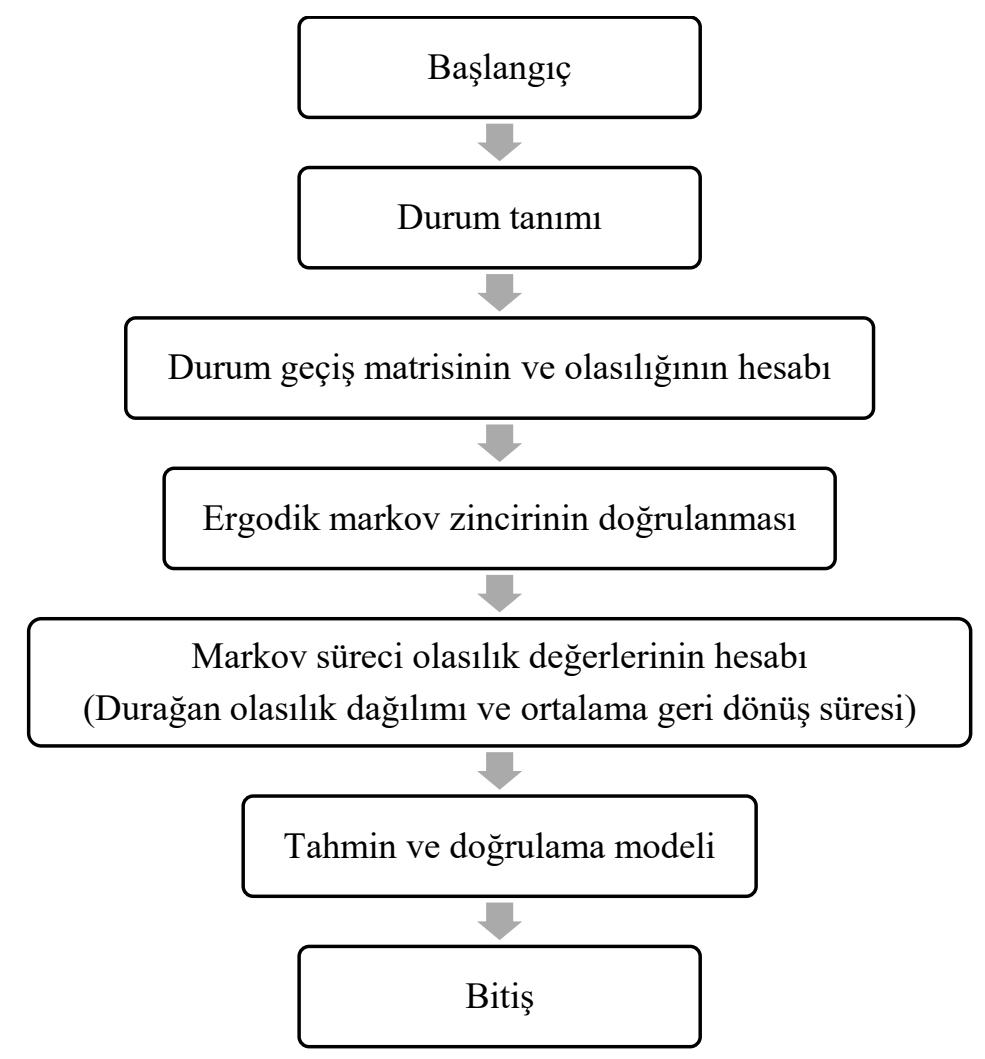

Şekil 1. Küçük Ölçekli Markov Zinciri modelinin yapısı 
Hava kalitesinin tahmin edilmesi için önerilen Markov zinciri yönteminin algoritmaları aşağıda gösterildiği gibi beş adımdan oluşmaktadır.

\section{C.1.1. Markov Zincir İşlemi İçin Durumu Tanımlama}

Bu adımda, modelin geliştirilmesinde kullanılan verilere dayanarak Markov zinciri süreci için durumlar veya eşikler belirlenir.

\section{C.1.2. Durum Geçiş Matrisi N'yi Ve Durum Geçiş Olassllğ̆ P'yi Oluşturma}

Markov zinciri tarafından tanımlanan durum geçiş matrisi N, bir durumdan diğerine geçişi veya atlama sıklığını gösterir (Denklem 3).

$\mathrm{N}=\left[\begin{array}{ccccc}\mathrm{n}_{11} & \cdot & \cdot & \cdot & \mathrm{n}_{1 \mathrm{j}} \\ \cdot & \cdot & & & \cdot \\ \cdot & & \cdot & & \cdot \\ \cdot & & & \cdot & \cdot \\ \mathrm{n}_{\mathrm{i} 1} & \cdot & \cdot & \cdot & \mathrm{n}_{\mathrm{ij}}\end{array}\right]$

Burada; $\mathrm{n}_{\mathrm{ij}}, \mathrm{j}$ durumundan i durumuna geçiş sayısıdır. $\mathrm{P}$, Markov zincir modelinin her durumu için tüm geçiş olasılıklarını tanımlayan bir geçiş matrisi veya stokastik matrisidir ve Denklem (4 ve(5'deki gibi gösterilir.

$P=\left[\begin{array}{ccccc}p_{11} & \cdot & \cdot & \cdot & p_{1 j} \\ \cdot & \cdot & & & \cdot \\ \cdot & & \cdot & & \cdot \\ \cdot & & & \cdot & \cdot \\ p_{i 1} & \cdot & \cdot & \cdot & p_{i j}\end{array}\right], i, j \in I$

$P\left\{X_{t+1}=j \mid X_{t}=i\right\}=P_{i j}$

P terimi, tek adımlı olasılık içindir. t zamanından bağımsız geçiş olasılıkları için homojen veya durağan Markov zincirini gösterir.

$P\left\{X_{t+1}=j \mid X_{t}=i\right\}=P\left\{X_{1}=j \mid X_{0}=i\right\}=p_{i j}$

Denklem (6'daki P matrisi, negatif olmayan öğelerin satır toplamı birliğini göstermektedir.

$0 \leq p_{i j} \leq 1$ ve $\sum_{j=1}^{t} p_{i j}=1, \sqrt{i} \in I$

Olasılık, k adımlarında i durumundan j durumuna $\mathrm{k}$ adımlı geçiş olasılığıdır. Geçiş matrisi P, Denklem (8 ve (9'daki özelliklere sahiptir.

$p_{i j}(k)=P\left\{X_{n+k}=j \mid X_{n}=i\right\}, \sqrt{k}>0, n \geq 0, i, j \in I$

$P(n)=p^{n-1} \times P=P^{n}$ 


\section{C.1.3. Ergodik Markov Zincirinin Doğrulanması}

P'nin durumunu sınıflandırarak bu zincirde sınırlayıcı dağılımın varlığını belirlemek için ergodik bir Markov zincirinin onayı yapılmalıdır. Üç bölüme ayrılmaktadır; indirgenemez Markov zinciri, periyodik Markov zinciri ve tekrarlayan ve geçici durumlar $[25,26]$.

\section{İndirgenemez Markov Zinciri}

$\mathrm{n}>0$ olduğunda, $\mathrm{p}_{\mathrm{ij}}(\mathrm{n})=0$ ise, $\mathrm{i}$ durumuna $\mathrm{j}$ durumundan erişilebilir. Her iki durum da erişilebilir ve iletişim olarak söylenebilir, $\mathrm{i} \leftrightarrow \mathrm{j}$. İletişim ilişkisinin özellikleri [27]:

- Bütün i değerleri 0'dan büyük ve eşit olduğunda, i durumu j ile bağlantılıdır.

- i durumu j ile bağlantılıysa, j durumu da i ile bağlantılıdır.

- i durumu j ile bağlantılıyken $\mathrm{j}$ de $\mathrm{k}$ ile bağlantılıysa, i de $\mathrm{k}$ ile bağlantılıdır.

İki durum aynı sınıfta iletişim kurduğunda, Markov zinciri sadece bir sınıf varsa indirgenemez olarak değerlendirilebilir.

\section{Periyodik Markov Zinciri}

$\mathrm{n}$ değeri d ye bölünmüyorsa ve $\mathrm{d}$ en büyük tam sayı ise $\mathrm{p}_{\mathrm{ii}}^{(\mathrm{n})}=0$ eşitse, $\mathrm{i}$ durumu periyottur. Her durumda periyodu olan böyle durumlarda markov zinciri periyodiktir.

\section{Tekrarlayan ve Geçici Durumlar}

Markov zincirinde, herhangi bir i durumu için fi, i durumunda başlayan bir olasıllı olabilir ve süreç i durumunda tekrar eder. fi $=1$ ise i durumu tekrarlı ve fi $<1$ ise i durumu geçici sayllabilir [18]. Sonlu bir Markov zinciri için, durum i Denklem (10'da gösterilmiştir.

$$
\sum_{n=1}^{\infty} P_{i j}^{(n)}=\infty
$$

i durumu tekrarlıysa durumun tekrar i'ye dönmesine kadar geçen süre kısitlıdır. Tüm tekrarlayan durumların pozitif tekrarlayan olduğunu göstermektedir. Pozitif tekrarlayan ve periyodik durumlar, ergodik olarak değerlendirilebilir [25].

\section{C.1.4. Markov süreci olasılık dĕgerleri}

Bu adımda Markov proses olasılık değerleri için durağan olasılık dağılımı ve ortalama geri dönüş süresi elde edilebilir. Durağan olasılık dağılımı, zincirin uzun bir süre için yeterli olduğu ve başlangıç koşullarından bağımsız olan kararlı durum olasılıklarıyla uzun vadeli tahminlerde hava kirliliğinin davranışını tanımlayacaktır. Ergodik bir Markov zinciri için dağılım sınırlayıcıdır ve Denklem (11'de gösterilmiştir.

$\Pi_{j}=\lim _{n \rightarrow \infty} P\left(X_{n}=j \mid X_{0}=i\right)$

$\mathrm{Bu}$ nedenle, $\mathrm{j}$ işlemi durumunda bulma olasıllı̆̆ , işlemdeki uzun bir süre için başlangıç durumuna bakılmaksızın yapılır [25]. j durumunun gerçekleşme olasılığı yüksek ise $\Pi_{j}$ değeri yüksek olacaktır [26]. Uzun vadeli davranış tahmini, bilgi eksikliği ve birikmiş hatalar gibi çeşitli problemler var ise dezavantaja sahiptir. Ayrıca, $m_{i j}$ parametresinin, belirli durumların kendisine geri dönmesi için ortalama geri dönüş süresinin hesaplanması gerekir (Denklem (12). 


$$
\mathrm{m}_{\mathrm{ij}}=\frac{1}{\Pi_{\mathrm{j}}}
$$

\section{C.1.5. Tahmin Ve Model Doğrulama}

Tahmin değeri, ilk olasılık ve durum geçiş olasılığından Denklem 13'e göre hesaplanır.

$P\left(S_{j}\right)=\sum_{i=1}^{n} P\left(S_{i}\right) P_{i j}$

$\mathrm{P}\left(\mathrm{S}_{\mathrm{i}}\right)$, başlangıç olasılığını, $\mathrm{P}_{\mathrm{ij}}$ ise durum geçiş olasılığını ifade etmektedir.

\section{2. Ayrık Zamanlı Markov Zinciri Modeli}

Zamandan bağımsız bir stokastik süreç olan Markov zinciri [28], kategorik verileri analiz etmek için birçok alanda yaygın olarak kullanılmaktadır [11] Markov zincirleri, çevresel izleme verilerinin gerçek davranışını analiz etmek, rüzgar gücü dağılımını tahmin etmek [29], çevresel izleme verilerinin zaman serisi verilerini tahmin etmek [30], hava kirleticilerinin konsantrasyonunu tahmin etmek [31] ve hava kirliliği kontrol politikalarını değerlendirmek [32] için kapsamlı bir şekilde uygulanmıştır.

Bir Markov zinciri tahmini, bir değişkenin belirli bir periyodunun gelecekteki durumu hakkında sonuç çıkarmak için başlangıç durum olasılık vektörüne ve geçiş olasıllı̆̆ matrisine dayanır [11]. Buna ilaveten Markov zinciri süreci, yalnızca mevcut duruma bağlı olarak ve geçmiş durumlarla ilgisiz olarak gelecekteki duruma geçişin koşullu olasılığını da dikkate alır [33]. Markov zincir dizisi verilerini, $\mathrm{S}_{1}, \mathrm{~S}_{2}, \ldots, \mathrm{S}_{m}$ ile temsil edilen çok sayıda farklı duruma dönüştürür. Durum geçişi yalnızca $t_{1}, t_{2}, \ldots, t_{m}$ zamanlarında gerçekleşir. Markov zincirinin $S_{i}$ durumuna $\mathrm{k}$ adım geçişleri aracılığıyla $S_{j}$ durumuna geçiş olasıllğ $1 p_{i j}$ ile Denklem(14'deki gibi ifade edilir:

$p_{i j}=\frac{m_{i j}}{M_{i}}$

$\mathrm{M}_{i}, \mathrm{~S}_{i}$ durumunun toplam sayısıdır, $\mathrm{m}_{i j}$ ise $\mathrm{S}_{i}$ durumunun $\mathrm{k}$ adımlı $\mathrm{S}_{j}$ durumuna geçiş süreleridir ve m'de durum sayısıdır. Bu nedenle, tek adımlı durum geçiş olasılığı matrisi Denklem (15'teki gibidir:

$\mathrm{P}=\left[\begin{array}{ccccc}\mathrm{p}_{11} & \mathrm{p}_{12} & \cdot & \cdot & \mathrm{p}_{1 \mathrm{~m}} \\ \mathrm{p}_{21} & \mathrm{p}_{22} & \cdot & \cdot & \mathrm{p}_{2 \mathrm{~m}} \\ \cdot & \cdot & \cdot & & \cdot \\ \cdot & \cdot & & \cdot & \cdot \\ \mathrm{p}_{\mathrm{m} 1} & \mathrm{p}_{\mathrm{m} 2} & \cdot & \cdot & \mathrm{p}_{\mathrm{mm}}\end{array}\right]$

Markov zinciri süreci, durum ve geçiş matrisi ile başlar. $t=0$ anındaki başlangıç hareketi verildiğinde, durum geçiş olasılık matrisi $\Pi^{0} \in \mathrm{S}^{\prime}$ dir. $\mathrm{k}$ sayıdaki gelişimden sonra, gelecekteki $\Pi^{\mathrm{k}}$ durumunun durum geçiş olasılı̆̆ 1 , geçiş matrisi P ve Denklem (16-(18 arasında verilen adımlar kullanılarak hesaplanabilir:

$\Pi^{1}=\Pi^{0} \times \mathrm{P}$

$\Pi^{2}=\Pi^{1} \times \mathrm{P}=\Pi^{0} \times \mathrm{P}^{2}$

$\Pi^{\mathrm{k}}=\Pi^{0} \times \mathrm{P}^{\mathrm{k}}$

Denklem (18'de belirtilen formül, durum geçiş olasılık matrisini hesaplamak için kullanılmaktadır [34]. Güvenilir bir geçiş olasılığı matrisi oluşturulduktan sonra maksimum alt indekse bağlı olarak HKİ 
kolayca tahmin edilebilmektedir. Hava kalitesi indeksini tahmin etmek için ayrık-zamanlı Markov zinciri modelinin uygulanmasında Denklem (19 kullanılmaktadır.

$\overline{\mathrm{HKI}}=\sum_{j=1}^{n} \Pi_{j} \times$ maks. $\left[H K \dot{\mathrm{I}}_{P M_{10}}, H K \dot{\mathrm{I}}_{S O_{2}}, H K \dot{\mathrm{I}}_{C O}, H K \dot{\mathrm{I}}_{N O_{2}}, H K \dot{\mathrm{I}}_{O_{3}}\right]$

Denklem (19'da, $\Pi_{j}$ her bir durumun sabit durum olasılı̆̆ıdır, bu da sistemin bu durumda olma olasılığ anlamına gelmektedir; maks. $\left[H K \dot{\mathrm{I}}_{i}\right]$, beş temel hava kirleticisi arasındaki maksimum HKİ değerini temsil eder.

\section{MARKOV ZINCIRİ MODELLERININ UYGULANMASI}

Nevşehir İli hava kalitesi indeksini tahmin etmek için kullandığımız Markov zinciri modellerinin uygulanması aşağıdaki 6 adımda detaylı olarak anlatılmıştır.

\section{1. Veri Setinin Hazırlanması}

Geçerli bir tahmin modeli oluşturmak için uygun bir veri seti gereklidir. Bu yüzden en ayrıntılı adımlardan biridir. Çalışma veri setini iki kategoriye ayrılmıştır. 1) Modellerin eğitimi için 01.08.201919.11.2020 tarih aralğındaki Nevşehir İli HKİ değerleri kullanılmıştı;; 2) Modellerin performansını doğrulamak için 20.11.2020-20.12.2020 tarihleri arasında kalan Nevşehir İli HKİ değerleri kullanılmıştır.

\section{2. Hava Kalitesi Durumunun Ve Değişkenlerinin Tanımlanması}

$\mathrm{Bu}$ adımın amacı, hava kalitesi izleme verilerinin stokastik davranışına bağlı olarak bir sistemin durumunu karakterize etmektir. Küçük ölçekli Markov zinciri modelinin tasarımında HKİ değerine bağlı olarak Tablo 1'de gösterilen 6 adet indeks tanımı ve değerleri kullanılmıştır. Ayrık zamanlı markov zinciri modelinin tasarımında ise 2 adet kategori oluşturulmuştur; hava kalitesi iyi durumdaysa değeri 0 , kötü durumda ise 1 alınmıştır. Ayrıca bu değerlere bağlı 5 birincil kirletici için toplam $2^{5}$ (32) adet senaryo oluşturulmuştur. Oluşturulan senaryolara ait görsel Şekil 1'de verilmiştir.

\section{3. Hava Kirleticilerinin Konsantrasyon Eşiğinin Belirlenmesi}

Hava kirleticilerinin konsantrasyon eşikleri, HKİ değerinin tahmin edilmesinde hangi hava kirleticilerinin ana katkı maddesi olarak kabul edileceğini belirleyen kriterdir. Tablo 1'de verilen eşik değerleri ve buna bağlı olarak kategori isimleri Ulusal Hava Kalitesi İndeksi Eşik Değerleri’ne göre belirlenmiştir [35].

\section{4. Durum Geçiş Matrisinin Oluşturulması}

Hava kalitesi durumları ve konsantrasyon eşikleri tanımladıktan sonra, hava kalitesi durumlarının geçiş olasılıklarını temsil eden geçiş matrisini oluşturmak için Markov zinciri modelleri uygulanmıştır. Geçiş olasılıkları, belirli sayıda geçiş içerdiğinde daha kararlı hale gelmektedir.

\section{5. Markov Zinciri Modellerinin Geliştirilmesi}

Hem küçük ölçekli hem de ayrık-zamanlı Markov zinciri modelleri 01.08.2019-19.11.2020 tarihleri arasında Nevşehir İli HKİ değerleri baz alınarak geliştirilmiştir. 


\section{6. Markov Zinciri Modellerinin Doğrulanması}

Modeller geliştirildikten sonra HKİ tahmin modellerinin performansını kontrol etmek için 20.11.202020.12.2020 tarihleri arasında sahada ölçülen HKİ değerleri ile modellerin tahminleri karşılaştırılmıştır. Bu çalışma, stokastik karakteristiğe dayalı olarak model doğrulama için haftalık ve aylık düzeyde izlenen HKİ verileri referans alınmıştır ve performans değerlendirmesi için t-testi yapılmıştır.

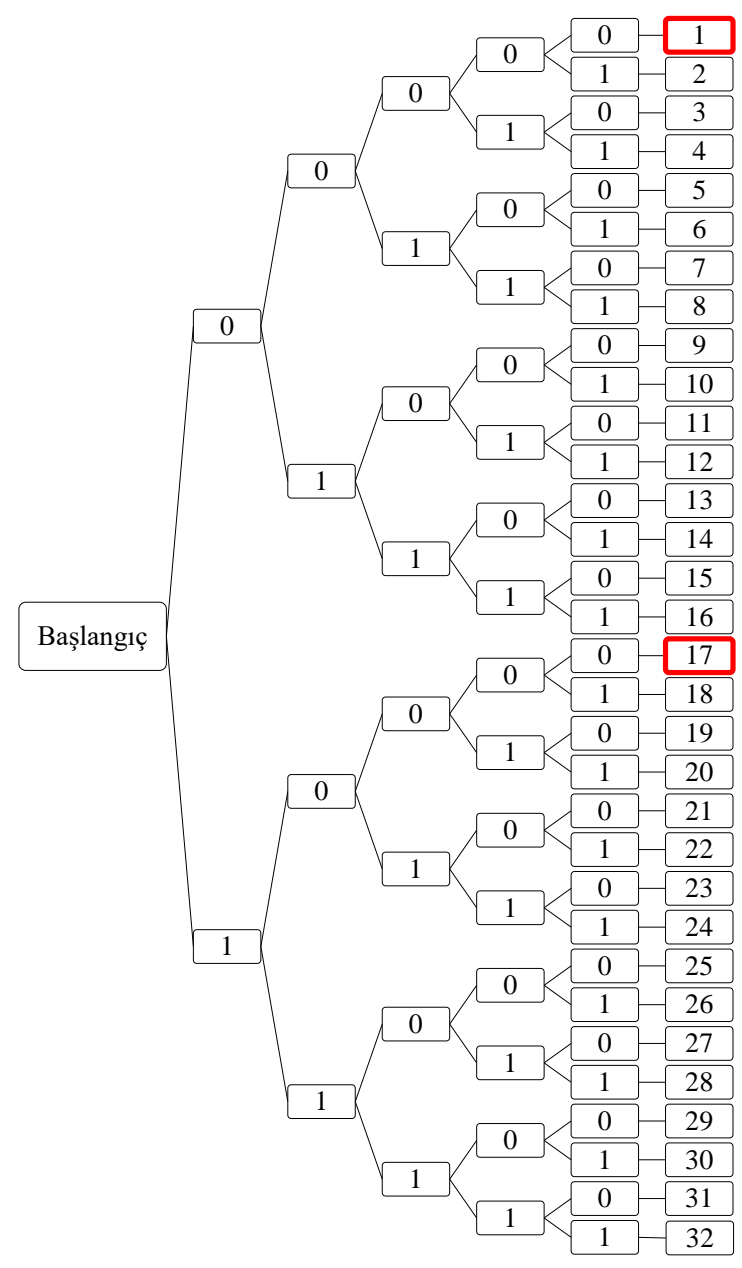

Şekil 2. Ayrı-zamanlı Markov zinciri model tasarımında kullanılan senaryolar

\section{BULGULAR ve TARTISMA}

\section{A. NEVŞEHIR ILII HAVA KALITESİ DURUMU}

Hava kalitesi de hava durumu gibi gün içerisinde çok değişkenlik gösterebilir. Resmi kurumlar, mevcut hava kalitesi hakkında farkındalığını artırma ve kontrol politika/stratejilerinin etkinliğini değerlendirme amacıyla sürekli olarak temel hava kirletici parametrelerini izleyerek veri toplarlar [36]. Bazı hava kirleticileri ölüm ve hastalık oranlarındaki artışlarla ilişkilendirilebilir. Başlıca hava kirleticileri partikül madde $\left(\mathrm{PM}_{10}\right)$, sülfür dioksit $\left(\mathrm{SO}_{2}\right)$, karbon monoksit $(\mathrm{CO})$, nitrojen oksitler $\left(\mathrm{NO}_{\mathrm{x}}\right)$ ve yer seviyesindeki ozon $\left(\mathrm{O}_{3}\right)$ 'dur [37]. Nevşehir İli'nde izlenilen hava kalite parametrelerine dair istatistiksel bilgiler Tablo 2'de sunulmuştur. 
Tablo 2. Nevşehir İli hava kirleticilerinin istatistiksel değerleri

\begin{tabular}{llllll}
\hline & \multicolumn{1}{c}{$\begin{array}{c}\mathrm{PM}_{10} \\
\left(\mu \mathrm{g} \mathrm{m}^{-3}\right)\end{array}$} & \multicolumn{1}{c}{$\begin{array}{c}\mathrm{SO}_{2} \\
\left(\mu \mathrm{g} \mathrm{m}^{-3}\right)\end{array}$} & $\begin{array}{c}\mathrm{CO} \\
\left(\mu g \mathrm{~m}^{-3}\right)\end{array}$ & $\begin{array}{c}\mathrm{NO}_{2} \\
\left(\mu g \mathrm{~m}^{3}\right)\end{array}$ & \multicolumn{1}{c}{$\begin{array}{c}\mathrm{O}_{3} \\
\left(\mu g \mathrm{~m}^{-3}\right)\end{array}$} \\
\hline Veri Say1s1 & 455 & 460 & 456 & 282 & 433 \\
En küçük & 8,440 & 0,660 & 65,890 & 7,670 & 1,250 \\
Ortalama & 40,008 & 10,167 & 450,708 & 34,330 & 45,177 \\
En büyük & 136,790 & 99,670 & 2053,25 & 82,310 & 103,760 \\
Standart Sapma & 21,113 & 14,329 & 269,761 & 13,950 & 25,321 \\
\hline
\end{tabular}

$\mathrm{PM}_{10}$, atmosferde asılı duran inorganik ve organik maddelerin sıvı ve katı partiküllerinin karmaşık bir karışımını içerir. PM'in genel kimyasal içeriği organik ve elementel karbondan, nitrat, sülfat gibi inorganik türlerden, poliaramotik hidrokarbonlar gibi organik türlerden, toprak elementlerinden ve metallerden oluşmaktadır. Buna ilaveten biyolojik türlerin de katkısı vardır. Atmosferik partikül madde çok çeşitli kaynaklardan yayılır [38]. Nevşehir İlinde PM $_{10}$ 'nun, toprak ve cadde tozu, biyolojik parçacıklar, volkanik emisyonlar ve orman yangınları gibi doğal kaynaklardan ve araç emisyonları, fosil yakıtların yakılması, inşaat ve endüstriyel faaliyetler, katı atık yakma ve biyokütle yakma gibi antropojenik kaynaklardan atmosfere salındığı düşünülmektedir [38].

Nevşehir İlinde kükürt dioksitin ( $\left.\mathrm{SO}_{2}\right)$, doğal (örn., toprak oksidasyonu ve hidrojen sülfür oksidasyonu) ve antropojenik faaliyetler (örn., metal eritme, biyokütlenin yanması ve fosil yakıtın yakılması) sonucu oluştuğu ve atmosfere yayıldığı düşünülmektedir [39]. Gözle görülür bir hava kirletici olan atmosferik $\mathrm{SO}_{2}$, aerosol damlacıkları tarafından emildiğinde asit yağmurlarını oluşturabilir [4]. Ayrıca $\mathrm{SO}_{2}$, canlıların kardiyovasküler sistemine zarar verebilen bir solunum sistemi tahriş edicidir.

Motorlu araçlar, kentsel alanlarda $\mathrm{NO}_{\mathrm{x}}$ ve CO'nun başlıca emisyon kaynaklarıdır. Atmosferdeki $\mathrm{CO}, 1$ aydan fazla sürede yarılanmaktadır ve yüksek konsantrasyonda bulanabilmektedir. Bu nedenle $\mathrm{CO}$, yerel hava kalitesini yorumlamak için çok önemli bir hava kirliliği parametresidir [40]. DSÖ, asit yağmurunun ve $\mathrm{O}_{3}$ oluşumunun birincil öncüsü olan $\mathrm{NO}_{x}$ 'i hava kirliliğinin belirlenmesim de izlenmesi gereken önemli bir parametre olarak görmektedir. Meteorolojik koşullar hem $\mathrm{CO}$ hem de $\mathrm{NO}_{\mathrm{X}}$ konsantrasyonlarını önemli ölçüde etkilemektedir. Nevşehir İli hava kalitesinin belirlenmesi için takip edilen parametrelerin $\mathrm{HKI}_{\mathrm{i}}$ değerleri Şekil 3 'te gösterilmiştir.

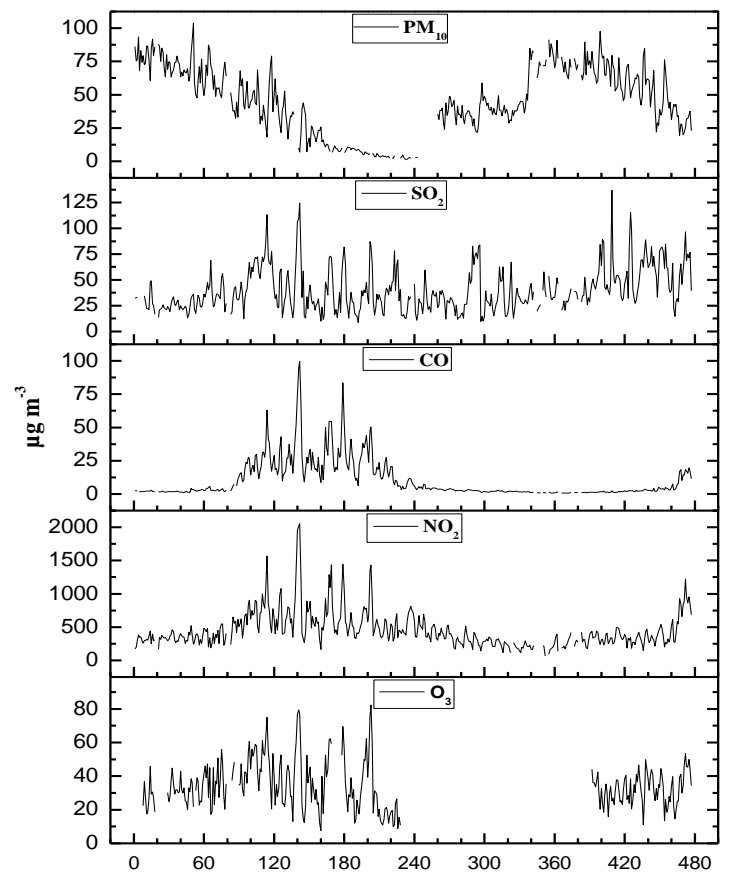

Şekil 3. Nevşehir İli hava kirletici konsantrasyonlarının günlük değişimi 
Şekil 3'te görüldüğü üzere, yaz aylarında $\mathrm{HKI}_{\mathrm{i}}$ sıralaması $\mathrm{PM}_{10}>\mathrm{O}_{3}>\mathrm{NO}_{2}>\mathrm{SO}_{2} \approx \mathrm{CO}$ iken, k1ş aylarında $\mathrm{PM}_{10}>\mathrm{NO}_{2} \approx \mathrm{SO}_{2}>\mathrm{O}_{3}>\mathrm{CO}$ olarak yapılabilmektedir. Tüm mevsimlerde HKİ üzerine en etkin parametre $\mathrm{PM}_{10}$ 'dur. Bunun temel sebebi Nevşehir İlinde mevsime bağlı olmaksızın sürekli olarak trafik, inşaat ve endüstriyel faliyetler gibi $\mathrm{PM}_{10}$ kaynaklarının bulunması ve bu kaynaklardan atmosfere salınım olmasıdır. Yaz aylarında, yüksek zemin sıcaklığı $\mathrm{CO}$ difüzyonunu ve $\mathrm{NO}_{x}{ }^{\prime i} \mathrm{O}_{3}$ 'e dönüştüren fotokimyasal reaksiyonu kolaylaştırdığından dolayı $\mathrm{O}_{3}$ konsantrasyonları artmıştır. Ayrıca, kış aylarında zemin sıcaklığının azalması nedeniyle nitrojen dioksitin $\left(\mathrm{NO}_{2}\right)$ mevsimsel dağılımına uyan $\mathrm{CO}$ dağılımı bozulmuştur.

Başlıca $\mathrm{HKI}_{\mathrm{i}}$ olan $\mathrm{PM}_{10}$ 'un ana bileşenleri arasında nitratlar, sülfatlar, sodyum klorür, amonyak, mineral tozu, siyah karbon ve su sayılabilir. Çapı $10 \mu \mathrm{m}$ veya daha az olan ince partiküller akciğerlere ulaşıp derinlerine yerleşebilir. Bu nedenle $\mathrm{PM}_{10}$ 'un insan sağlığına en zararlı etkiye sahip parametre olduğu kabul edilmektedir. Dünya üzerinde yaklaşık üç milyon ölümün ve 85 milyon engelli kalmanın sebebi partikül maddelerden kaynaklanan hava kirliliği olduğu düşünülmektedir [41].

İkincil kirletici olan $\mathrm{O}_{3}$, güneş ışığının yardımıyla uçucu organik bileşikler ve $\mathrm{NO}_{\mathrm{x}}$ gibi öncüler tarafindan oluşturulur. Yeryüzü seviyesindeki $\mathrm{O}_{3}$ sadece insan sağlı̆̆ üzerinde zararlı bir etkiye sahip olmakla kalmaz aynı zamanda tarım arazilerine ve ekosistemlere de zarar verir. Literatürdeki çalışmalarda, yer seviyesine yakın bölgedeki $\mathrm{O}_{3}$ konsantrasyonunun çeşitli solunum problemleri ve akciğer hastalıkları ile pozitif ilişkili olduğunu ve $\mathrm{O}_{3}$ konsantrasyonundaki her $10 \mu \mathrm{g} \mathrm{m}^{-3}$ artışın kalp hastalığına bağlı günlük ölüm oranında \%0,3-0,4 artışa yol açabildiği tespit edilmiştir [42]. Diğer birincil kirleticilerden farklı olarak, $\mathrm{O}_{3}$ doğrusal olmayan kimyasal reaksiyonla üretilir ve konsantrasyonlar periyodiklik olmaksızın dalgalanır.

Hava kalitesini izlemek için artık gelişmiş teknolojik cihazlar kullanılıyor ve bu verileri halka duyurmak için periyodik raporlar yayınlanıyor. Genel olarak, ham veriler, zaman serisi grafikleri ve istatistiksel analizler yerine daha kolay anlaşılabilir olan HKİ verileri tercih ediliyor. Bu çalışmada beş temel hava kirleticinin konsantrasyonuna bağlı olarak Denklem (2'ye göre hesaplanan Nevşehir İli Hava Kalitesi İndeksi Şekil 4'te verilmiştir.

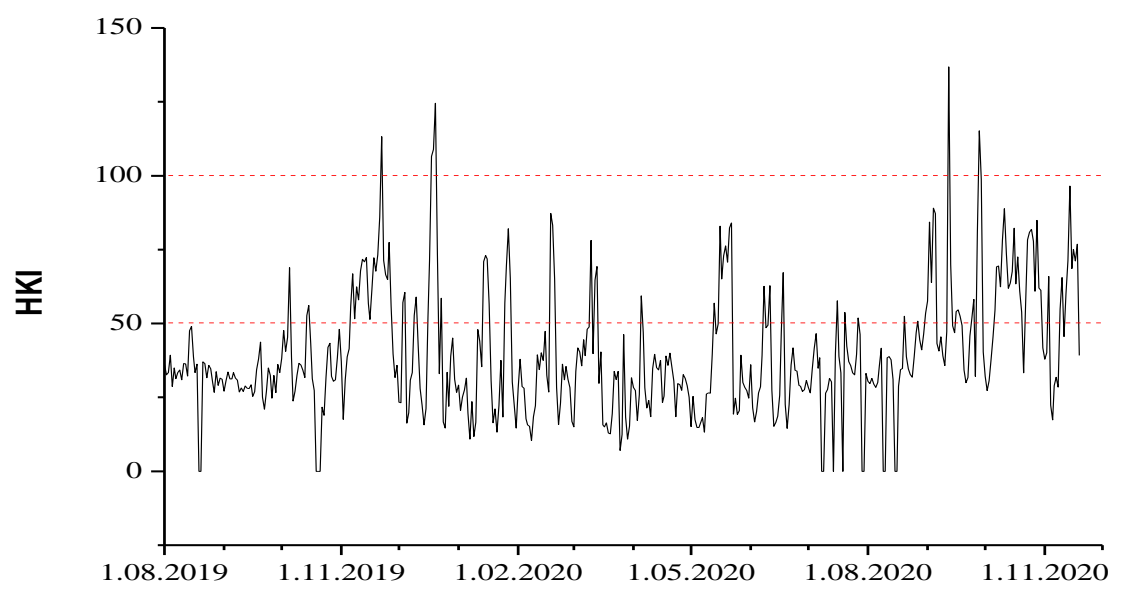

Şekil 4. Nevşehir İli HKİ değerlerinin günlük değişimi

Şekil 4'e göre, kimi zaman yaz aylarında kimi zaman da kış aylarında HKİ düşmüştür. HKİ değeri ortalama olarak 39,57 olmakla birlikte hava kalitesinin genelde iyi olduğu söylenebilmektedir. 


\section{B. MARKOV ZINCIR ANALIZİ İLE HAVA KALITESİ TAHMINI}

\section{B. 1. Küçük Ölçekli Markov Zinciri Modeli İle HKİ Tahmini}

Tablo 3'te zaman serileri için her bir HKİ durumunun frekanslarını listelenmiştir. En yüksek frekans hava kalitesinin iyi olduğu seviyede iken, hava kalitesinin sağlıksız olduğu duruma dair Nevşehir'de bir yıldan fazla bir süredir veri bulunmamaktadır.

Tablo 3. Küçük Ölçekli Markov Zinciri Modeli senaryolarına göre günlük HKİ değişim sıklı̆̆

\begin{tabular}{lcccccc}
\hline \multirow{2}{*}{ Mevcut Durum } & \multicolumn{7}{c}{ Gelecekteki Durum } \\
\cline { 2 - 7 } & İyi (1) & Orta (2) & Hassas (3) & Sağliksız (4) & Kötü (5) & Tehlikeli (6) \\
\hline İyi (1) & 328 & 31 & 1 & 0 & 0 & 0 \\
Orta (2) & 32 & 75 & 3 & 0 & 0 & 0 \\
Hassas (3) & 0 & 4 & 2 & 0 & 0 & 0 \\
Sağl1ksız (4) & 0 & 0 & 0 & 0 & 0 & 0 \\
Kötü (5) & 0 & 0 & 0 & 0 & 0 & 0 \\
Tehlikeli (6) & 0 & 0 & 0 & 0 & 0 & 0 \\
\hline
\end{tabular}

Çalışma döneminde HKİ'ye ilişkin gözlemler, 3 farklı geçiş durumu içerdiğini göstermektedir. Geçiş olasılığı, gelecekteki durum olasılığının ortaya çıkması ve sonrasında karar verme süreci hakkında fikir vermektedir. 477 günlük HKİ, iyi bir durum için sıklığın 360 gün, orta ve hassas durum için ise 110 gün ve 6 gün olduğunu göstermektedir. Denklem (5 kullanılarak hesaplanabilen HKİ'nin geçiş olasıllığı, hava kalitesinin bir durumdan başka bir duruma geçişine ilişkin bilgiler sağlamakta ve Denklem (20'de gösterildiği gibi hesaplanmıştır.

$\mathrm{P}_{\mathrm{HKI}}=\left[\begin{array}{lll}0,9111 & 0,0861 & 0,0028 \\ 0,2909 & 0,6818 & 0,0273 \\ 0,0000 & 0,6667 & 0,3333\end{array}\right]$

Örneğin, hava durumu iyi iken tekrar iyi olma ihtimali 328/360 (0,91111)'dir. Başl1k C. 1.'de bahsedilen 2.adıma dayalı olarak elde edilen bulgular, geliştirilen küçük ölçekli Markov zincir modelinin indirgenemez, periyodik olmayan ve tekrarlayan olduğunu göstermektedir. Böylece modelin ergodik bir Markov zinciri modeli olduğunu teyit edilmiştir. Uzun dönem hava kalitesi tahmini için durumların olasılığı, durağan olasılık dağılım değeri olarak isimlendirilmiştir. 3 farklı durum için Denklem (11 kullanılarak gelecekteki HKİ'nin kararlı durum olasılığı türetilmiştir.

$\pi_{j}=\left[\begin{array}{lll}0,7563 & 0,2311 & 0,0126\end{array}\right]$

$\pi_{j}$ iyi denge durumunun 0,7563 , orta derecenin 0.2311 ve hassasin 0.0126 olduğunu belirtir. Sağl1ksız durumun olmaması ve hassas durumdaki en düşük orana bağlı olarak gelecekte sis oluşma riski düşüktür. Ortalama geri döngü süresi bir durumun ortalama ne kadar süre aynı durumda kaldığını göstermektedir ve Denklem (12'ye göre hesaplanmıştır. Denklem (22'deki matriste gösterildiği gibi her HKİ durumu için ortalama geri döngü süresini belirlemek için sabit olasılık dağılımı kullanılmıştır.

$\mathrm{m}_{\mathrm{j}}=\left[\begin{array}{lll}1,3222 & 4,3271 & 79,3651\end{array}\right]$

Sonuçlar, iyi duruma olan ortalama geri döngü süresinin 1,3222 gün, orta dereceli duruma geri döngü süresinin 4,3271 gün ve hassas derceli duruma geri döngü süresinin ortalama 79 gün olduğunu göstermektedir. Gelecek günün HKİ olasılığı, başlangıç durum vektörü ile durum geçiş olasılığının çarpılmasıyla elde edilir. 477 günün sonunda sonundaki başlangıç durum vektörü iyi durumdur, bu nedenle $(1.0000,0.0000,0.0000)$ olarak alınmıştır ve Denklem (23'de hesap gösterilmiştir. 
$\eta_{(20.11 .2020)}=\eta_{(19.11 .2020) \times} \mathrm{P}_{\mathrm{HKI}}$

$\eta_{(20.11 .2020)}=\left[\begin{array}{lll}1,0000 & 0,0000 & 0,0000\end{array}\right]$

$\left[\begin{array}{lll}0,9111 & 0,0861 & 0,0028 \\ 0,2909 & 0,6818 & 0,0273 \\ 0,0000 & 0,6667 & 0,3333\end{array}\right]=\left[\begin{array}{lll}0,9111 & 0,0861 & 0,0028\end{array}\right]$

Küçük ölçekli markov zinciri modeli ile 478. günün hava kalitesinin 0,9111 olasilıkla iyi dereceli, 0,0861 olasılıkla orta dereceli ve 0,0028 olasılıkla hassas dereceli olacağ tahmin edilmiştir.

\section{B. 2. Ayrık Zamanlı Markov Zinciri Modeli İle HKİ Tahmini}

Her kirletici ve durum geçiş matrisinin bir önceki günde tahmin edilen HKİ değeri kullanılarak bir sonraki gündeki HKİ hesaplanabilmektedir. Denklem (24-(27'de sunulan veriler ayrık zamanlı markov zinciri modelinin 478. günün HKİ tahminini göstermek için kullanılmıştır. 477. Günün hava kalitesi, tüm hava kirleticilerinin Tablo 1'e göre iyi durumda bulunduğu zaman yani Durum-Temiz'e göre iyi olarak sınıflandırılmıştır.

$$
\begin{aligned}
& \mathrm{P}_{\mathrm{HKI}}=\left[\begin{array}{ll}
0,9111 & 0,0889 \\
0,2759 & 0,7241
\end{array}\right] \\
& \pi_{\mathrm{j}}=[0,7563 \quad 0,2437] \\
& m_{j}=[1,32224,1034]
\end{aligned}
$$

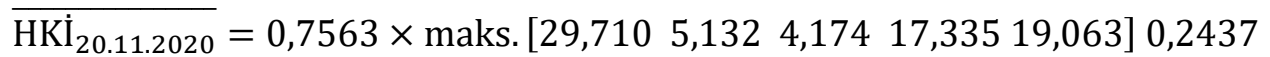

$$
\begin{aligned}
& \times \text { maks. }[(0,948 \times 67,513 \\
& +0,052 \times 117,547) 5,1324,17417,33519,063]=39,5533
\end{aligned}
$$

Denklem (27'de, ilk satırdaki maksimum HKİ $\dot{I}_{i}$ değeri, Durum-Temiz oluştuğunda HKİ değerini temsil eder (yani, temiz hava durumundaki tüm kirleticiler). İkinci satırda, parantez içerisindeki rakamlar, kirli hava olduğunda $\mathrm{HKI}_{\mathrm{i}}$ 'yi temsil eder. Beklenen HKİ değeri, her bir hava kirleticisinin konsantrasyon eşiğini belirlemek için Tablo 4'de gösterildiği gibi hesaplandı ve Şekil 2 ve Tablo 5, hava kalitesini

\begin{tabular}{|c|c|c|c|c|c|c|c|}
\hline Kirletici & \multicolumn{3}{|c|}{$\mathrm{PM}_{10}$} & $\mathrm{SO}_{2}$ & $\mathrm{CO}$ & $\mathrm{NO}_{2}$ & $\mathrm{O}_{3}$ \\
\hline Kategori & Temiz & \multicolumn{2}{|c|}{ Kirli } & Temiz & Temiz & Temiz & Temiz \\
\hline HKİ Kat. & 0 & 2 & 3 & 0 & 0 & 0 & 0 \\
\hline En küçük & 8,440 & 51,37 & 106,6 & 0,333 & 0,611 & 3,873 & 0,527 \\
\hline Ortalama & 29,71 & 67,51 & 117,6 & 5,132 & 4,174 & 17,34 & 19,06 \\
\hline En büyük & 50,79 & 98,76 & 136,8 & 50,33 & 19,04 & 41,56 & 43,73 \\
\hline Kat. Veri & 339 & 110 & 6 & 460 & 456 & 282 & 433 \\
\hline Veri, \% & 1,000 & 0,948 & 0,052 & 1,000 & 1,000 & 1,000 & 1,000 \\
\hline
\end{tabular}
Durum-Temiz olarak tanımlamak için kullanıldı.

Tablo 4. Ayrık Zamanlı Markov Zinciri Modeli senaryolarına göre Nevşehir İli hava kirliliği parametrelerinin istatistikleri

Tablo 5. Ayrık Zamanlı Markov Zinciri Modeli senaryolarına göre günlük HKİ değişim sıklı̆̆ı

\begin{tabular}{lcc}
\hline \multirow{2}{*}{ Mevcut Durum } & \multicolumn{2}{c}{ Gelecekteki Durum } \\
\cline { 2 - 3 } & Temiz $(00000)$ & Kirli (10000) \\
\hline Temiz (00000) & 328 & 32 \\
Kirli (00010) & 32 & 84 \\
\hline
\end{tabular}




\section{MODELLERIN DOĞRULANMASI VE KARŞILAŞTIRILMASI}

Nevşehir İli hava istasyonundan alınan 477 günlük hava kalitesi parametrelerini içeren veri seti ile eğitilen düşük ölçekli ve ayrık zamanlı Markov zinciri modellerinin doğrulama çalışması eğitim verileri haricinde 30 günlük hava kalite indeksi veri seti de eklenerek gerçekleştirilmiştir. Toplamda 507 veri içereden doğrulama çalışmasında elde edilen bulgular Şekil 5 ve Tablo 6'da sunulmuştur.

a) Küçük Ölçekli Markov Zinciri Modeli

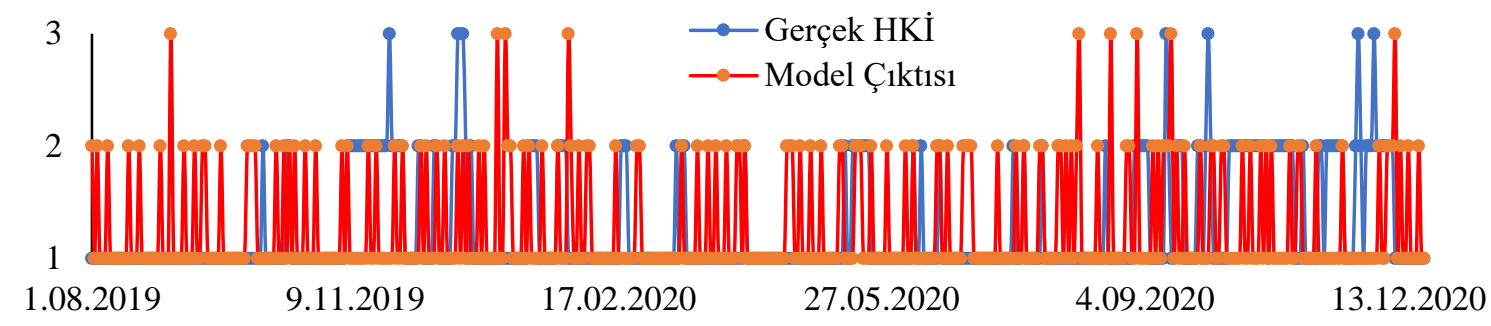

b) Ayrık Zamanlı Markov Zinciri Modeli

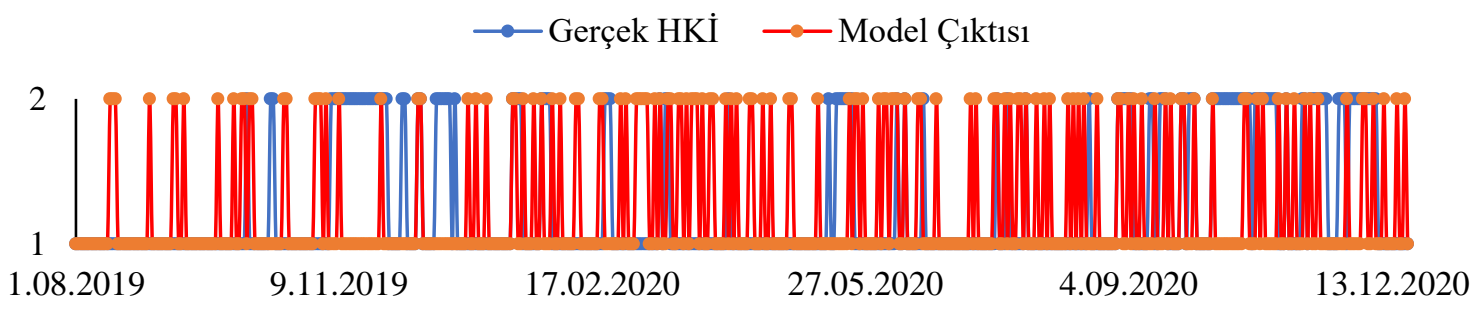

Şekil 5. Ayrık Zamanlı (a) ve Kü̧̈ük Ölçekli (b) Markov Zinciri Modellerinin kiyaslanması

Şekil 5.a'da görüldüğü gibi küçük ölçekli Markov zinciri modeli Tablo 1'de gösterilen 6 durumdan yalnızca ilk 3 durumu (iyi, orta ve hassas) içermekte iken ayrık-zamanlı Markov zinciri modeli ise Şekil 2 'de gösterilen 32 senaryodan yalnızca Senaryo 1 ve Senaryo 17 olmak üzere toplam 2 adet durumu (temiz [00000], kirli [10000]) içermektedir. Bu çalışmada daha az değişken duruma sahip olan ayrıkzamanlı Markov zinciri modeli hem eğitiminde hem de doğrulanmasında kullanılan HKİ verilerini tahmin etmede daha başarılı bulunmuştur. Başarım göstergeleri Tablo 6'da sunulan model çıktıları ile gerçek HKİ verileri arasındaki durumların gerçekleşme sıklı̆̆ kıyaslamasından yani korelasyon katsayılarından da açıkca görülmektedir.

Tablo 6. Ayrık Zamanlı ve Küçük Ölçekli Markov Zinciri Modellerinin kıyaslanması

\begin{tabular}{|c|c|c|c|c|c|c|}
\hline \multirow[b]{2}{*}{ Durum } & \multicolumn{2}{|c|}{ Frekans } & \multirow[b]{2}{*}{$\mathrm{R}^{2}$} & \multicolumn{2}{|c|}{ Frekans } & \multirow[b]{2}{*}{$\mathrm{R}^{2}$} \\
\hline & Gerçek & $\begin{array}{c}\text { Küçük ölçekli } \\
\text { Markov } \\
\text { Zinciri }\end{array}$ & & Gerçek & $\begin{array}{c}\text { Ayrik } \\
\text { Zamanlı } \\
\text { Markov } \\
\text { Zinciri } \\
\end{array}$ & \\
\hline 1 & 0,756 & 0,744 & 0,983 & 0,756 & 0,750 & 0,991 \\
\hline 2 & 0,231 & 0,239 & 0,968 & 0,244 & 0,250 & 0,973 \\
\hline 3 & 0,013 & 0,018 & 0,710 & & - & \\
\hline
\end{tabular}

\section{IV.SONUC}

$\mathrm{Bu}$ çalışmada, 01.08.2019-19.11.2020 tarihleri arasında Nevşehir İli hava istasyonundan $\mathrm{PM}_{10}, \mathrm{SO}_{2}$, $\mathrm{CO}, \mathrm{NO}_{2}$ ve $\mathrm{O}_{3}$ gibi temel hava kirletici parametreleri verileri alınarak günlük HKİ değerleri hesaplanmıştır. 15 aylık veriye göre Nevşehir İli hava kalitesi iyi ve hassas HKİ derecelerinde değişkenlik göstermektedir. Daha sonra Nevşehir İli günlük HKİ değerlerinin tahmin edilmesi için 
küçük ölçekli ve ayrık zamanlı Markov Zinciri Modelleri geliştirilip kıyaslanmıştır. Küçük ölçekli Markov Zinciri Modeli, HKİ kategorileri kadar yani 6 adet durum içermesine rağmen Nevşehir İlinde sadece 3 durum gözlemlenmiştir. Ayrıca, Ayrık Zamanlı Markov Zinciri Modeli de toplam 32 adet durum değişkenine sahip olmasına rağmen bunlardan sadece 2'si Nevşehir İlinde gerçekleşmiştir. Ayrık zamanlı Markov Zinciri Modelinin Nevşehir İlindeki hava kalitesine bağlı olarak küçük ölçekli Markov Zinciri Modeline nazaran daha az durum değişkeni içermesinden dolay1 01.08.2019-20.12.2020 tarihleri arasındaki HKİ değerlerini tahmin etmede daha başarılı olduğu görülmüştür. Bunun yanı sıra, Markov Zinciri modelleri ile hava kalitesi tahmini yapılmasının mümkün olduğu da kanıtlanmıştır.

TEȘEKKÜR: Yapılan bu çalışmada yazımında manen destek veren değerli iş arkadaşlarımıza ve hocalarımıza teşekkür ederiz.

\section{KAYNAKLAR}

[1] L. Yang, M. Li, W. Li, Y. Jiang, and Z. Qiang, "Bench-and pilot-scale studies on the removal of pesticides from water by VUV/UV process," Chemical Engineering Journal, vol. 342, pp. 155-162, 2018.

[2] Y. J. Wu and J.-C. Chen, "A structured method for smart city project selection," International Journal of Information Management, pp. 101981, 2019.

[3] World Health Organization, "WHO Air quality guidelines for particulate matter, ozone, nitrogen dioxide and sulfur dioxide: global update 2005: summary of risk assessment, Geneva, Switzerland, WHO/SDE/PHE/OEH/06.02, 2006.

[4] Y.-Y. Lee, Y.-K. Hsieh, G.-P. Chang-Chien, and W. Wang, "Characterization of the air quality index in southwestern Taiwan," Aerosol and Air Quality Research, vol. 19, no. 4, pp. 749-785, 2019.

[5] K. N. Andersen, J. A. Nielsen, and S. Kim, "Use, cost, and digital divide in online public health care: lessons from Denmark," Transforming Government: People, Process and Policy, pp. 197-211, 2019.

[6] J. P. S Sidhu, W. Ahmed, W. Gernjak, R. Aryal, D. McCarthy, A. Palmer, P. Kolotelo, and S. Toze, "Sewage pollution in urban stormwater runoff as evident from the widespread presence of multiple microbial and chemical source tracking markers," Science of the Total Environment, vol. 463, pp. 488-496, 2013.

[7] U.S. Environmental Protection Agency, "A guide to air quality and your health," New York, USA, EPA-456/F-14-002, 2009.

[8] C. Zhu, R. Fan, J. Sun, M. Luo, and Y. Zhang, "Exploring the fluctuant transmission characteristics of Air Quality Index based on time series network model," Ecological Indicators, vol. 108, pp. 105681, 2020.

[9] X. Yang, Z. Zhang, Z. Zhang, L. Sun, C. Xu, and L. Yu, "A long-term prediction model of Beijing haze episodes using time series analysis," Computational Intelligence and Neuroscience, vol. 2016, 2016.

[10] P. Hajek and V. Olej, "Predicting common air quality index-the case of czech microregions," Aerosol and Air Quality Research, vol. 15, no. 2, pp. 544-555, 2015.

[11] Y. Qi and S. Ishak, "A Hidden Markov Model for short term prediction of traffic conditions on freeways," Transportation Research Part C: Emerging Technologies, vol. 43, pp. 95-111, 2014. 
[12] J. R. Crusoe and K. Ahlin, "Users' activities for using open goandrnment data-a process framework," Transforming Goandrnment: People, Process and Policy, pp. 213-236, 2019.

[13] S. Elgharbi, M. Esghir, O. Ibrihich, A. Abarda, S. El Hajji, and S. Elbernoussi, "Grey-Markov Model for the prediction of the electricity production and consumption," in International Conference on Big Data and Networks Technologies, Leuven, Belgium: Springer, 2019, pp. 206-219.

[14] R. P. Sen, "Markov versus non-markov processes," in Operations Research: Applications And Algorithms, Eastern Economy Ed., New Delhi: PHI Learning Private Limited, 2012, vol. 3.

[15] C. Chatfield, "Statistical inference regarding Markov chain models," Journal of the Royal Statistical Society: Series C (Applied Statistics), vol. 22, no. 1, pp. 7-20, 1973.

[16] K. Y. Chan and L. Jian, "Identification of significant factors for air pollution leandls using a neural network based knowledge discoandry system," Neurocomputing, vol. 99, pp. 564-569, 2013.

[17] N. Güler and Ö. G. İşçi, "The regional prediction model of $\mathrm{PM}_{10}$ concentrations for Turkey," Atmospheric Research, vol. 180, pp. 64-77, 2016.

[18] B. T. Ong, K. Sugiura, and K. Zettsu, "Dynamically pre-trained deep recurrent neural networks using environmental monitoring data for predicting PM 2.5," Neural Computing and Applications, vol. 27, no. 6, pp. 1553-1566, 2016.

[19] N. Suhaimi, N. A. Ghazali, M. Y. Nasir, M. I. Z. Mokhtar, and N. A. Ramli, "Markov Chain Monte Carlo method for handling missing data in air quality datasets," Malaysian Journal of Analytical Sciences, vol. 21, no. 3, pp. 552-559, 2017.

[20] L. Luo, F. Zhang, W. Zhang, L. Sun, C. Li, D. Huang, and B. Wang, "Markov chain-based acute effect estimation of air pollution on elder asthma hospitalization," Journal of Healthcare Engineering, vol. 2017, 2017.

[21] Á. Gómez-Losada, "Clustering air monitoring stations according to background and ambient pollution using hidden Markov models and multidimensional scaling," Data Science, pp. 123-132, 2017.

[22] A. Nebenzal and B. Fishbain, "Long-term forecasting of nitrogen dioxide ambient leandls in metropolitan areas using the discrete-time Markov model," Environmental Modelling \& Software, vol. 107, pp. 175-185, 2018.

[23] M. Nicas, "Markov modeling of contaminant concentrations in indoor air," AIHAJ-American Industrial Hygiene Association, vol. 61, no. 4, pp. 484-491, 2000.

[24] A. Plaia and M. Ruggieri, "Air quality indices: a review," Reviews in Environmental Science and Bio/Technology, vol. 10, no. 2, pp. 165-179, 2011.

[25] M. H. Chi, "The long-run behavior of Markov chains," Linear Algebra And Its Applications, no. 244, pp. 111-121, 1996.

[26] C. M. Grinstead and J. L. Snell, Grinstead and Snell's Introduction to Probability: The CHANCE Project, USA: American Mathematical Society, 2006.

[27] H. J. Fernando, M. C. Mammarella, G. Grandoni, P. Fedele, R. Di Marco, R. Dimitrova, and P. Hyde, "Forecasting $\mathrm{PM}_{10}$ in metropolitan areas: Efficacy of neural networks," Environmental Pollution, vol. 163 , pp. 62-67, 2012.

[28] S. M. Ross, Introduction To Probability Models, 11th ed., USA: Elsevier Academic Press, 2014. 
[29] N. J. Vickers, "Animal communication: when i'm calling you, will you answer too?," Current Biology, vol. 27, no. 14, pp. R713-R715, 2017.

[30] A. D. Sahin and Z. Sen, "First-order Markov chain approach to wind speed modelling," Journal of Wind Engineering and Industrial Aerodynamics, vol. 89, no. 3-4, pp. 263-269, 2001.

[31] E. R. Rodrigues, M. H. Tarumoto, and G. Tzintzun, "Application of a non-homogeneous Markov chain with seasonal transition probabilities to ozone data," Journal of Applied Statistics, vol. 46, no. 3, pp. 395-415, 2019.

[32] L. Hoyos, P. Lara, E. Ortiz, R. L. Bracho, and J. González, "Evaluation of air pollution control policies in Mexico City using finite Markov chain observation model," Revista de Matemática: Teoría y Aplicaciones, vol. 16, no. 2, pp. 255-266, 2009.

[33] S. A. Kalogirou, "Artificial neural networks in renewable energy systems applications: a review," Renewable and Sustainable Energy Reviews, vol. 5, no. 4, pp. 373-401, 2001.

[34] R. Liu and Y. Ge, "Smart home system design based on Internet of Things," in 12th International Conference on Computer Science and Education (ICCSE), 2017, pp. 444-448.

[35] T. C. Çevre and Şehircilik Bakanlığı. (2021, 23 Nisan). Hava kalitesi izleme sistemi [Çevrimiçi]. Erişim:

https://sim.csb.gov.tr/Home/HKI?baslik=HAVZA\%20\%C4\%B0ZLEME\%20S\%C4\%B0STEM\%C4\% B0

[36] Ü. A. Şahin $v d$., "Temporal variations of atmospheric black carbon and its relation to other pollutants and meteorological factors at an urban traffic site in Istanbul," Atmospheric Pollution Research, vol. 11, no. 7, pp. 1051-1062, 2020.

[37] M. Krzyzanowski and A. Cohen, "Update of WHO air quality guidelines," Air Quality, Atmosphere \& Health, vol. 1, no. 1, pp. 7-13, 2008.

[38] A. Dolar ve H. T. K. Saraç, "Türkiye'nin doğu illerindeki hava kalitesinin $\mathbf{P M}_{10}$ yönüyle incelenmesi,” Iğdır Üniandrsitesi Fen Bilimleri Enstitüsü Dergisi, c. 5, no. 4, ss. 25-32, 2015.

[39] W. Wang, K. Cui, R. Zhao, L.-T. Hsieh, and W.-J. Lee, "Characterization of the air quality index for Wuhu and Bengbu cities, China," Aerosol and Air Quality Research, vol. 18, no. 5, pp. 1198-1220, 2018.

[40] J.-C. Chen and Y. J. Wu, "Discrete-time Markov chain for prediction of air quality index," Journal of Ambient Intelligence and Humanized Computing, pp. 1-10, 2020.

[41] World Health Organization, Air Quality Guidelines: Global Update 2005: Particulate Matter, Ozone, Nitrogen Dioxide, And Sulfur Dioxide, Copenhagen, Denmark: World Health Organization Regional Office for Europe, 2006.

[42] I. Suryati, H. Khair, and D. Gusrianti, "Analysis of air quality index distribution of $\mathrm{PM}_{10}$ and $\mathrm{O}_{3}$ concentrations in ambient air of Medan City, Indonesia," Journal of Physical Science, vol. 29, pp. 37$48,2018$. 